\title{
Complete genome analysis of a virulent Vibrio scophthalmi strain VSc190401 isolated from diseased marine fish half- smooth tongue sole, Cynoglossus semilaevis
}

Zheng Zhang ${ }^{1,2^{*}}\left(\mathbb{D}\right.$, Yong-xiang Yu ${ }^{1}$, Yin-geng Wang ${ }^{1,2^{*}}$, Xiao Liu ${ }^{1}$, Li-fang Wang ${ }^{1}$, Hao Zhang ${ }^{1}$, Mei-jie Liao ${ }^{1,2}$ and Bin $\mathrm{Li}^{1}$

\begin{abstract}
Background: Vibrio scophthalmi is an opportunistic bacterial pathogen, which is widely distributed in the marine environment. Earlier studies have suggested that it is a normal microorganism in the turbot gut. However, recent studies have confirmed that this bacterial strain can cause diseases in many different marine animals. Therefore, it is necessary to investigate its whole genome for better understanding its physiological and pathogenic mechanisms.

Results: In the present study, we obtained a pathogenic strain of $V$. scophthalmi from diseased half-smooth tongue sole (Cynoglossus semilaevis) and sequenced its whole genome. Its genome contained two circular chromosomes and two plasmids with a total size of 3,541,838 bp, which harbored 3185 coding genes. Among these genes, 2648, 2298, and 1915 genes could be found through annotation information in COG, Blast2GO, and KEGG databases, respectively. Moreover, 10 genomic islands were predicted to exist in the chromosome I through IslandViewer online system. Comparison analysis in VFDB and PHI databases showed that this strain had 334 potential virulencerelated genes and 518 pathogen-host interaction-related genes. Although it contained genes related to four secretion systems of T1SS, T2SS, T4SS, and T6SS, there was only one complete T2SS secretion system. Based on CARD database blast results, 180 drug resistance genes belonging to 27 antibiotic resistance categories were found in the whole genome of such strain. However, there were many differences between the phenotype and genotype of drug resistance.
\end{abstract}

Conclusions: Based on the whole genome analysis, the pathogenic V. scophthalmi strain contained many types of genes related to pathogenicity and drug resistance. Moreover, it showed inconsistency between phenotype and genotype on drug resistance. These results suggested that the physiological mechanism seemed to be complex.

Keywords: Vibrio scophthalmi, Bacterial genome, Pathogenicity, Virulence factors, Drug resistance

\footnotetext{
* Correspondence: zhangzheng@ysfri.ac.cn; wangyg@ysfri.ac.cn

${ }^{1}$ Key Laboratory of Maricultural Organism Disease Control, Ministry of

Agriculture and Rural Affairs, Yellow Sea Fisheries Research Institute, Chinese

Academic of Fishery Sciences, Qingdao, Shandong 266071, PR China

${ }^{2}$ Laboratory for Marine Fisheries Science and Food Production Processes,

Pilot National Laboratory for Marine Science and Technology (Qingdao),

Qingdao, Shandong 266237, PR China
}

(c) The Author(s). 2020, corrected publication 2020. Open Access This article is licensed under a Creative Commons Attribution 4.0 International License, which permits use, sharing, adaptation, distribution and reproduction in any medium or format, as long as you give appropriate credit to the original author(s) and the source, provide a link to the Creative Commons licence, and indicate if changes were made. The images or other third party material in this article are included in the article's Creative Commons licence, unless indicated otherwise in a credit line to the material. If material is not included in the article's Creative Commons licence and your intended use is not permitted by statutory regulation or exceeds the permitted use, you will need to obtain permission directly from the copyright holder. To view a copy of this licence, visit http://creativecommons.org/ licenses/by/4.0/. The Creative Commons Public Domain Dedication waiver (http://creativecommons.org/publicdomain/zero/1. 0/) applies to the data made available in this article, unless otherwise stated in a credit line to the data. 


\section{Background}

Vibrio scophthalmi was first isolated from larval turbot (Scophthalmus maximus) intestine by Spanish scientists in 1997 and identified as a new species of Vibrio genus [1]. In terms of phylogenetic status, this bacterium shares very high gene sequence similarity and amino acid identity with Vibrio ichthyoenteri [2]. Moreover, they also have similar physiological and biochemical characteristics [3]. $V$. ichthyoenteri is considered as a causative agent of Japanese flounder intestinal disease (Paralichthys olivaceus). Earlier studies have suggested that V. scophthalmi is a type of common organism colonized in the turbot (Scophthalmus maximus) gut, which is not pathogenic and has certain host specificity for turbot [4]. Subsequently, this bacterium is successively isolated from diseased Paralichthys olivaceus [5], Paralichthys dentatus [6], Dentex dentex [7], Ruditapes philippinarum [8] and Thunnus maccoyii [9], supporting its pathogenicity to aquatic animals.

Current studies have proved that $V$. scophthalmi is an opportunistic pathogen [5], and it generally does not cause diseases when it is in the intestine of healthy fish. However, when the fish are subjected to environmental stress and their immunity is weakened, they are easily infected by this bacterial strain, leading to disease or death. For example, if the water temperature rises to $20^{\circ} \mathrm{C}$, eel (Anguilla japonica) is easy to be infected by $V$. scophthalmi, which results in symptoms of severe enteritis and ascites, leading to high mortality [10]. $V$. scophthalmi can be a secondary agent to significantly increase the mortality of diseased fish after the infections of other pathogens [5]. Scientists have confirmed that V. scophthalmi is one of the main pathogenic bacteria for Japanese flounder (P. olivaceus) cultured in Jeju area of Korean [11]. It is also a major pathogen of cultured turbot in China [12]. The typical symptoms of $V$. scophthalmi-infected fish include body surface blackening, ascites, enteritis, and internal organ hyperaemia $[5,13]$, leading to 30 to $90 \%$ mortality of infected fish and huge economic losses.

It is generally believed that extracellular substances, including proteases and exotoxins, are the key virulence factors for most pathogenic Vibrio bacteria [14]. However, the pathogenic mechanism of $V$. scophthalmi still remains largely unexplored until now. Previous studies have confirmed that the extracellular products of $V$. scophthalmi show a variety of protease activities, such as naphthol-AS-BI-phosphohydrolase, lipase, gelatinase, and leucine arylamidase [15], while no hemolytic activity or cytotoxic effect has been reported. Besides, some studies have shown that $V$. scophthalmi exhibits resistance to a variety of antibiotics $[16,17]$.

In the present study, a strain of $V$. scophthalmi was isolated from diseased half-smooth tongue sole (Cynoglossus semilaevis), and its pathogenicity to fish was verified by artificial infection experiment. Subsequently, the whole genome of this strain was sequenced and analyzed in detail. Collectively, our findings provided valuable insights into molecular mechanisms underlying the pathogenicity of $V$. scophthalmi and drug resistance.

\section{Results and discussion}

\section{The pathogenicity of strain VSc190401}

The diseased half-smooth tongue sole naturally infected by strain VSc190401 showed an apparent abdominal lump (Fig. 1a). After dissection, effusion flowed out from the abdominal cavity. The internal organs exhibited serious hyperemia, and the intestinal tract became thin and transparent, which was filled with a large amount of effusion and white pus (Fig. 1b). The mortality rate of this case was more than $40 \%$.

During the artificial challenge test, the fish in the negative control group and blank control group remained healthy and showed no symptoms. The half-smooth tongue sole artificially infected in the experiment group with strain VSc190401 also showed the same symptoms as the naturally infected fish, such as effusion in the abdominal cavity, internal organ hyperemia, and thin and transparent intestine. The artificially infected turbot did not appear abdominal lump, while the organ hyperemia and intestinal inflammation were observed. Artificial infection confirmed that the $V$. scophthalmi strain VSc190401 had strong pathogenicity to fish.

\section{Genomic information of strain VSc190401}

After assembly, the size of the whole genome of $V$. scophthalmi strain VSc190401 was 3,541,838 bp, including two circular chromosomes (Chr I 3,286,294 bp and Chr II 202,664 bp) with an approximate GC content of 45.00 and $45.37 \%$, respectively, and two plasmids (plasmid I 24,538 and plasmid II 28,342 bp) with an approximate GC content of 43.32 and $43.41 \%$, respectively. The strain contained 3185 coding genes, among which Chr I consisted of 2943 CDSs, 104 tRNA genes, and 37 rRNA genes. Chr II contained 188 CDSs. Plasmid I contained 32 CDSs, and plasmid II contained 22 CDSs. Figure 2 shows the genome information.

\section{Phylogenetic analyses}

ANI analysis showed that $V$. scophthalmi strain VSc190401 was clustered with $V$. scophthalmi VS-12 and VS-05 in the whole genome of eight selected strains, and there were some genetic differences (Fig. 3). The annotation information in the NCBI database indicated that $V$. scophthalmi VS-12 and VS-05 strains were all isolated from Japanese flounder cultured in Korea, containing three and two plasmids in addition to two chromatins, respectively. Based on the ANI analysis, the whole genome of $V$. scophthalmi strain VSc190401 was found to be genetically different 


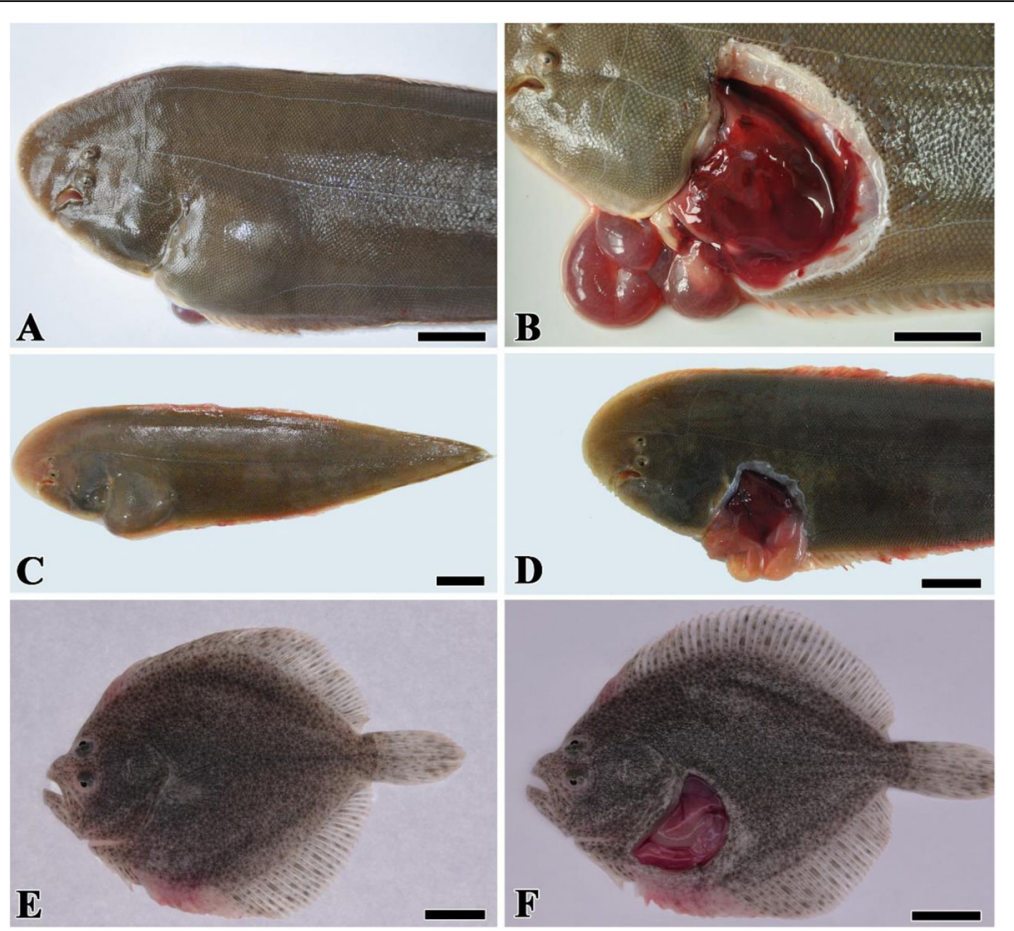

Fig. 1 The symptoms of diseased fish with natural infection and artificial infection V. scophthalmi strain VSc190401. a: Naturally infected halfsmooth tongue sole had obvious abdominal lump. b: Naturally infected half-smooth tongue sole showed serious internal organ hyperemia and enteritis. c: Artificially infected half-smooth tongue soles showed the same symptoms of abdominal limp. d: Artificially infected half-smooth tongue soles appeared the same internal organ lesions as the naturally infected case. e: Artificially infected turbot did not appear abdominal lump. f: Artificially infected turbot showed serious organ hyperemia and enteritis. Bar $=2 \mathrm{~cm}$

compared with Korean isolate strains VS-12 and VS-05, suggesting that there were some differences in host diversity or pathogenicity between Chinese and Korean isolates.

\section{Functional annotation}

COG annotation results showed that 2648 genes were annotated into 22 types of genes, accounting for $83.14 \%$ of total genes in $V$. scophthalmi strain VSc190401. The number of each type of gene was as follows: one A-type gene (RNA processing and modification), two B-type genes (chromatin structure and dynamics), 138 C-type genes (energy production and conversion), 36 D-type genes (cell cycle control, cell division, chromosome partitioning), 199 E-type genes (amino acid transport and metabolism), 68 F-type genes (nucleotide transport and metabolism), $128 \mathrm{G}$-type genes (carbohydrate transport and metabolism), $104 \mathrm{H}$-type genes (coenzyme transport and metabolism), 59 I-type genes (lipid transport and metabolism), $167 \mathrm{~J}$-type genes (translation, ribosomal structure and biogenesis), $135 \mathrm{~K}$-type genes (transcription), $192 \mathrm{~L}$-type genes (replication, recombination and repair), $161 \mathrm{M}$-type genes (cell wall/membrane/envelope biogenesis), $53 \mathrm{~N}$-type genes (cell motility), 118 O-type genes (posttranslational modification, protein turnover, chaperones), 147 P-type genes (inorganic ion transport and metabolism), 28 Q-type genes (secondary metabolites biosynthesis, transport and catabolism), $687 \mathrm{~S}$-type genes (function unknown), $140 \mathrm{~T}$-type genes (signal transduction mechanisms), 99 U-type genes (intracellular trafficking, secretion, and vesicular transport), and $41 \mathrm{~V}$-type genes (defense mechanisms) (Fig. 4). Supplementary Table S1 lists all COG functional annotation information.

The functional annotation results in the GO database showed that 2298 genes were annotated into three types of genes, which accounted for $72.15 \%$ of total genes of $V$. scophthalmi strain VSc190401. Among them, 1327 genes were related to the cellular component, 1850 genes were related to the molecular function, and 1795 were related to the biological process. The GO terms with the highest numbers of genes in the classification of the biological process were oxidation-reduction process (174 genes, 5.46\%) and regulation of transcription/DNAtemplated (141 genes, $4.43 \%)$. The GO terms with the highest numbers of genes in the classification of cellular components were integral components of membrane (641 genes, 20.13\%), cytoplasm (336 genes, 10.55\%), and plasma membrane (91 genes, 2.86\%). The GO terms with the highest numbers of genes in the classification of molecular function were ATP binding (281 genes, $8.82 \%)$, DNA binding $(244,7.66 \%)$, metal ion binding 

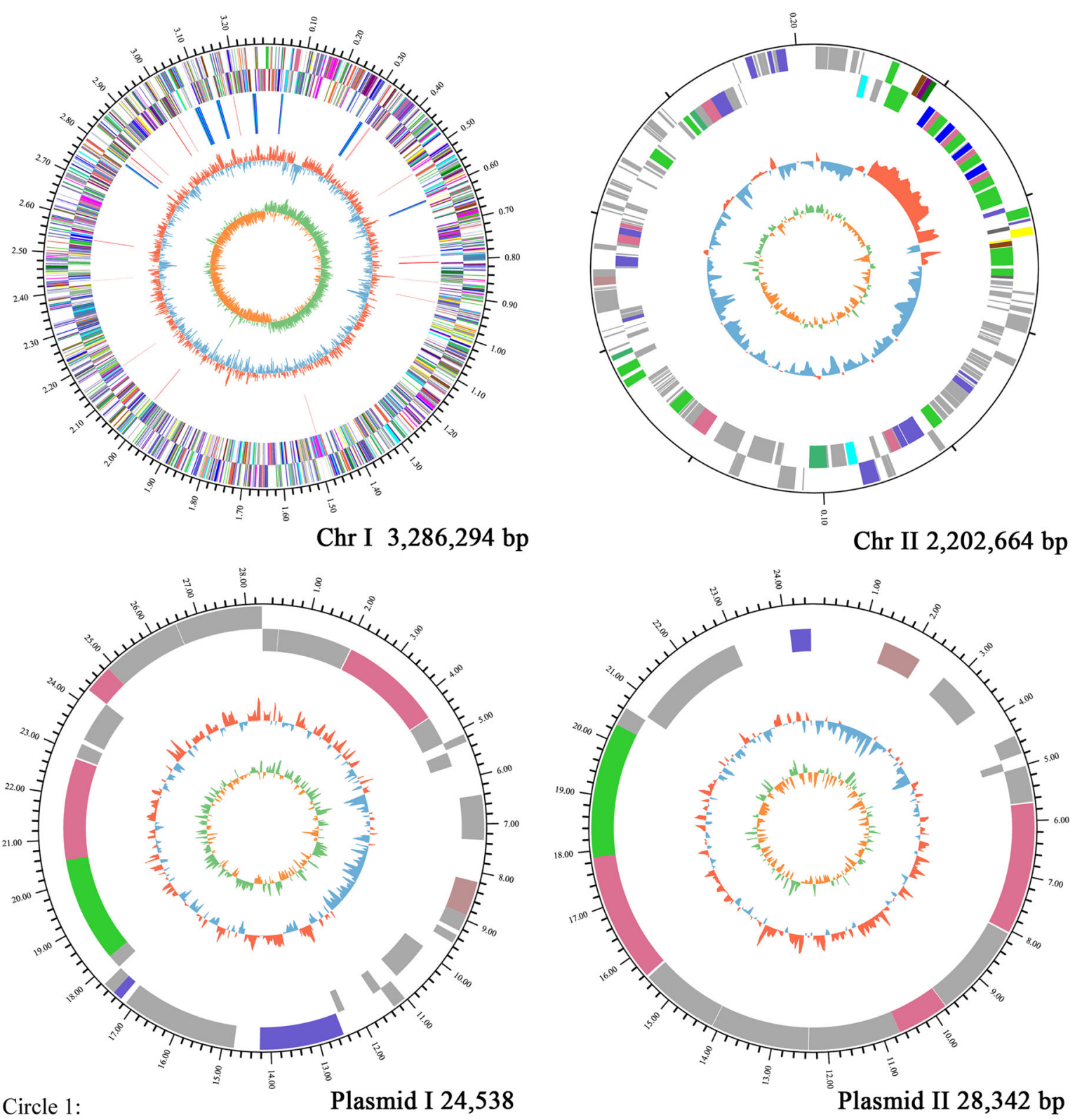

Circle 1:

Plasmid I 24,538
A : RNA processing and modification
B : Chromatin structure and dynamics
$\mathrm{C}$ : Energy production and conversion
D:Cell cycle control, cell division, chromosome partitioning
$\mathrm{E}$ : Amino acid transport and metabolism
$\mathrm{F}:$ Nucleotide transport and metabolism
G:Carbohydrate transport and metabolism
$\mathrm{H}:$ Coenzyme transport and metabolism
I : Lipid transport and metabolism
$\mathrm{J}$ : Translation, ribosomal structure and biogenesis
$\mathrm{K}$ : Transcription
$\mathrm{L}:$ Replication, recombination and repair
M: Cell wall/membrane/envelope biogenesis
$\mathrm{N}$ : Cell motility
O: Posttranslational modification, protein turnover, chaperones

$\mathrm{P}:$ Inorganic ion transport and metabolism

Q: Secondary metabolites biosynthesis, transport and catabolism

$\mathrm{R}$ : General function prediction only

$S:$ Function unknown

$\mathrm{T}:$ Signal transduction mechanisms

$\mathrm{U}$ : Intracellular trafficking, secretion, and vesicular transport

$\mathrm{V}$ : Defense mechanisms

W: Extracellular structures

$\mathrm{Y}:$ Nuclear structure

$\mathrm{Z}:$ Cytoskeleton

Circle 2:

口 16S_rRNA

23S rRNA

5S_rRNA

tRNA

Fig. 2 (See legend on next page.) 
(See figure on previous page.)

Fig. 2 Circular genome maps of V. scophthalmi strain VSc190401. Note: The outermost circle is the identification of genome size. The second and the third circle are the CDSs on the positive and negative strands, respectively, and different colors indicate the different functional annotations of CDSs in the COG database. The fourth circle is rRNA and tRNA. The fifth circle is the GC content, the red part outside indicates that the GC content of the region is higher than the average GC content of the whole genome, the blue part inward indicates that the GC content of the region is lower than the average GC content of the whole genome, and the higher peak value means the greater difference from the average GC content. The innermost circle is the GC-Skew value, and its algorithm is $\frac{G-C}{G+C}$, which can assist to determine the leading strand and lagging strand. In general, the leading strand GC-skew $>0$ and the lagging strand GC-skew $<0$. The green part outside means GC-skew $>0$, the orange part inward means GC-skew $<0$, and the higher peak value means larger value. The legend circle1 is the functional classification in the COG database, and the legend circle2 is a different RNA classification

(127 genes, 3.99\%), and transcription factor activity/sequence-specific DNA binding (82 genes, 2.57\%). More information was shown in Fig. 5. Supplementary Table S2 lists all GO functional annotation information.

The results of the KEGG pathway analysis showed that 1915 genes were annotated into 196 known metabolic pathways. The metabolic pathway with the largest number of genes was the biosynthesis of amino acids, containing 106 genes, followed by two-component system (96 genes), carbon metabolism (83 genes), ABC transporters (81 genes), and purine metabolism (65 genes). Cluster analysis showed that 196 metabolic pathways were categorized into six classifications of cellular processes, metabolism, human diseases, genetic information processing, organismal systems, and environmental information processing, and the numbers of genes in these six classifications were $235,1348,112,219,47$ and 268 , respectively (Fig. 6). The 235 genes in the classification of cellular processes could be divided into four categories, and most of them were clustered into cell motility (74 genes) and cellular community-prokaryotes (135 genes). The 1348 genes in the classification of metabolism were divided into 12 categories. The categories with the largest gene number included global and overview maps (242 genes), carbohydrate metabolism (256 genes), amino acid metabolism (202 genes), and metabolism of cofactors and vitamins (149). The 112 genes in the classification of human diseases were clustered into 10 categories, and the categories with the largest gene number were drug resistance: antimicrobial (37 genes), and infectious diseases: bacterial (27 genes) and neurodegenerative diseases (13 genes). The 219 genes in the classification of genetic information processing were clustered into four categories. The categories with the largest gene number were translation (79 genes), replication and repair (90 genes), and folding, sorting and degradation (46 genes). The 47 genes in the classification

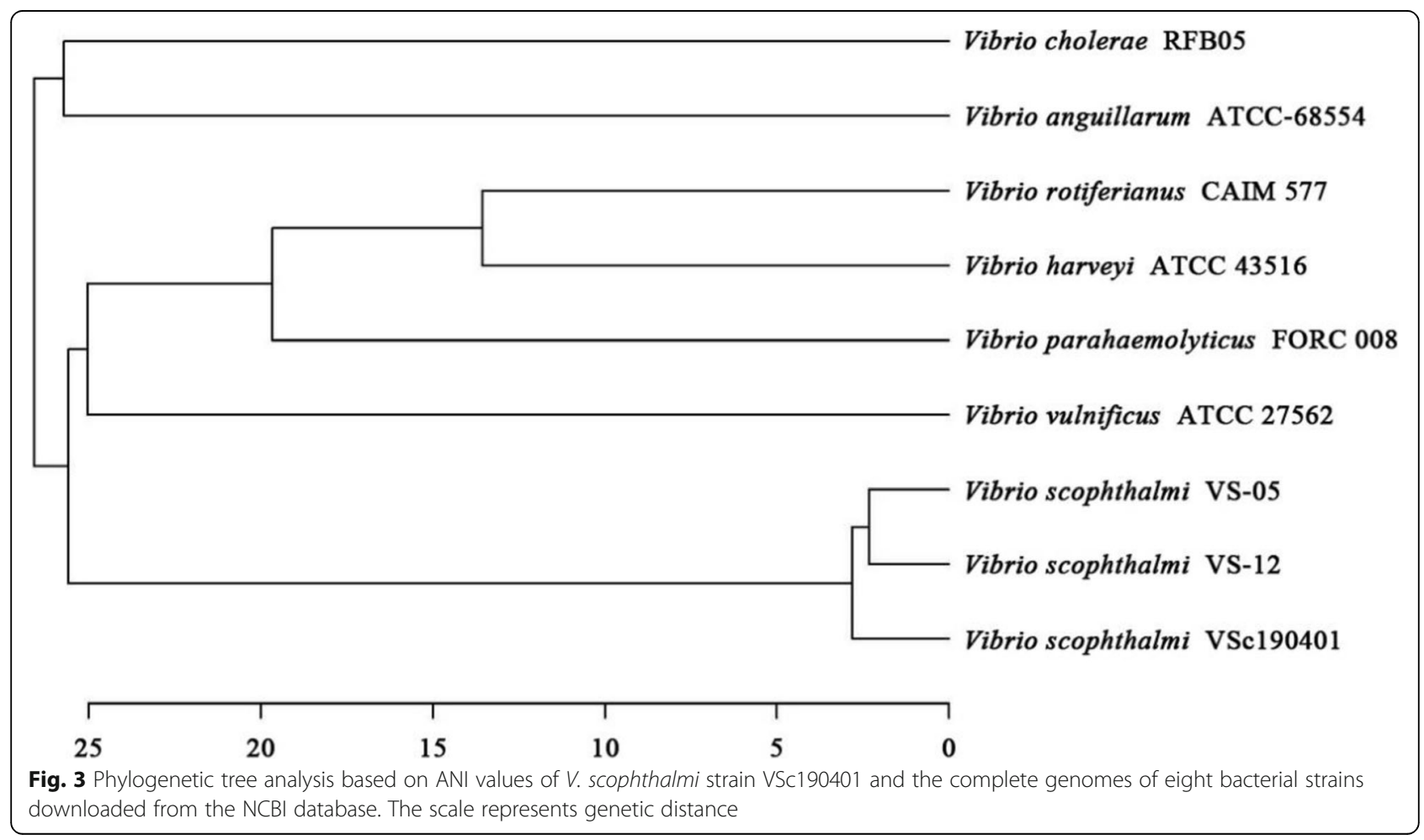




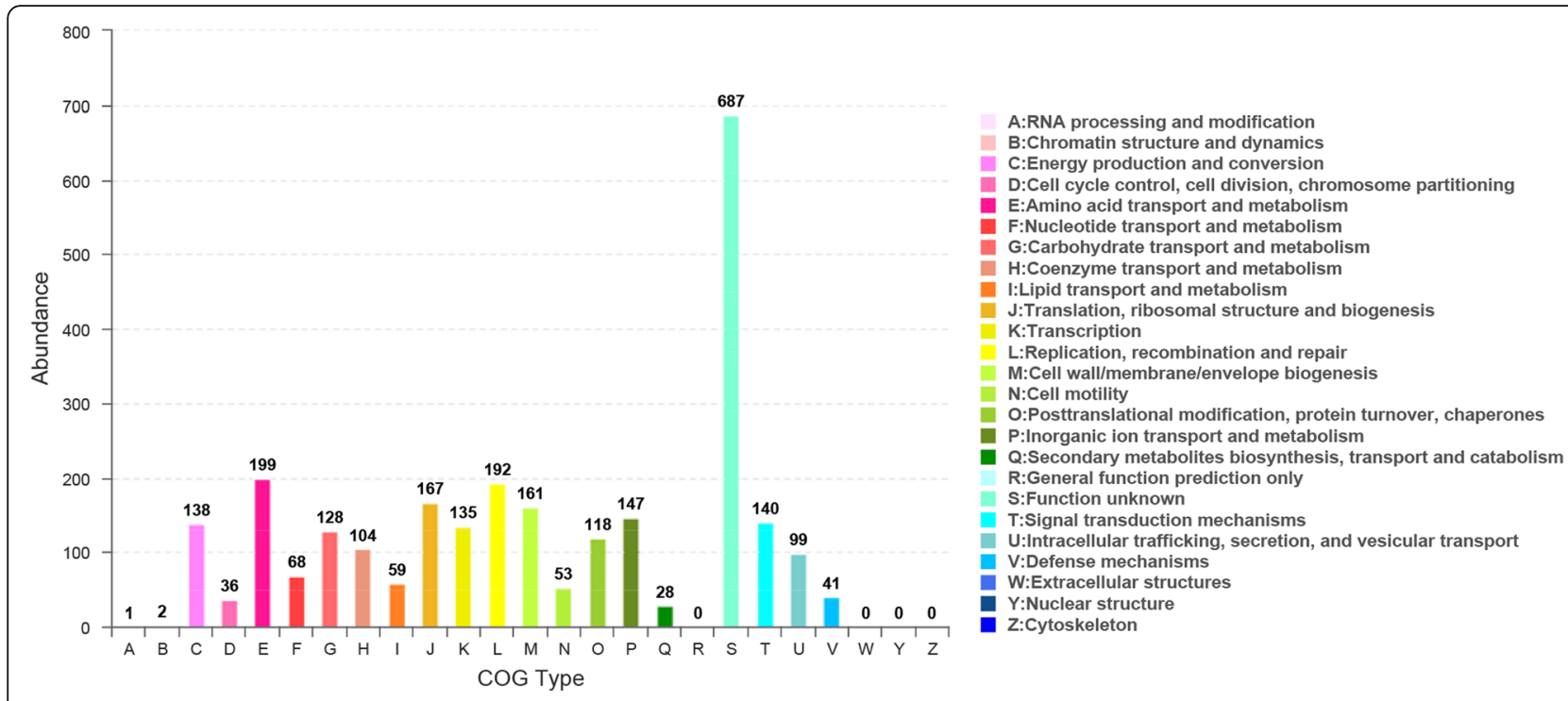

Fig. 4 COG functional annotation of CODs in the whole genome of V. scophthalmi strain VSC190401

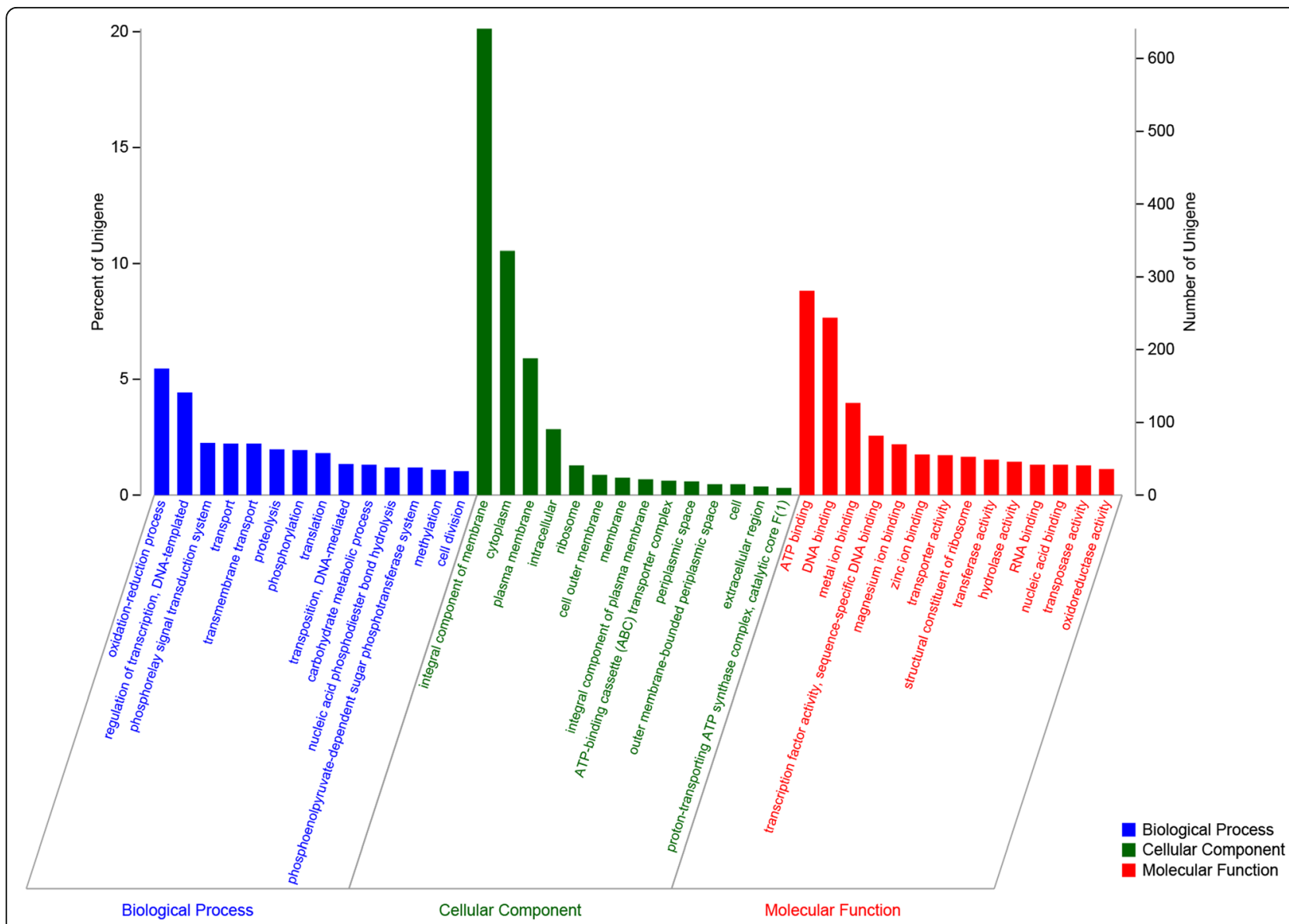

Fig. 5 GO functional annotation of CODs in the whole genome of V. scophthalmi strain VSc190401 


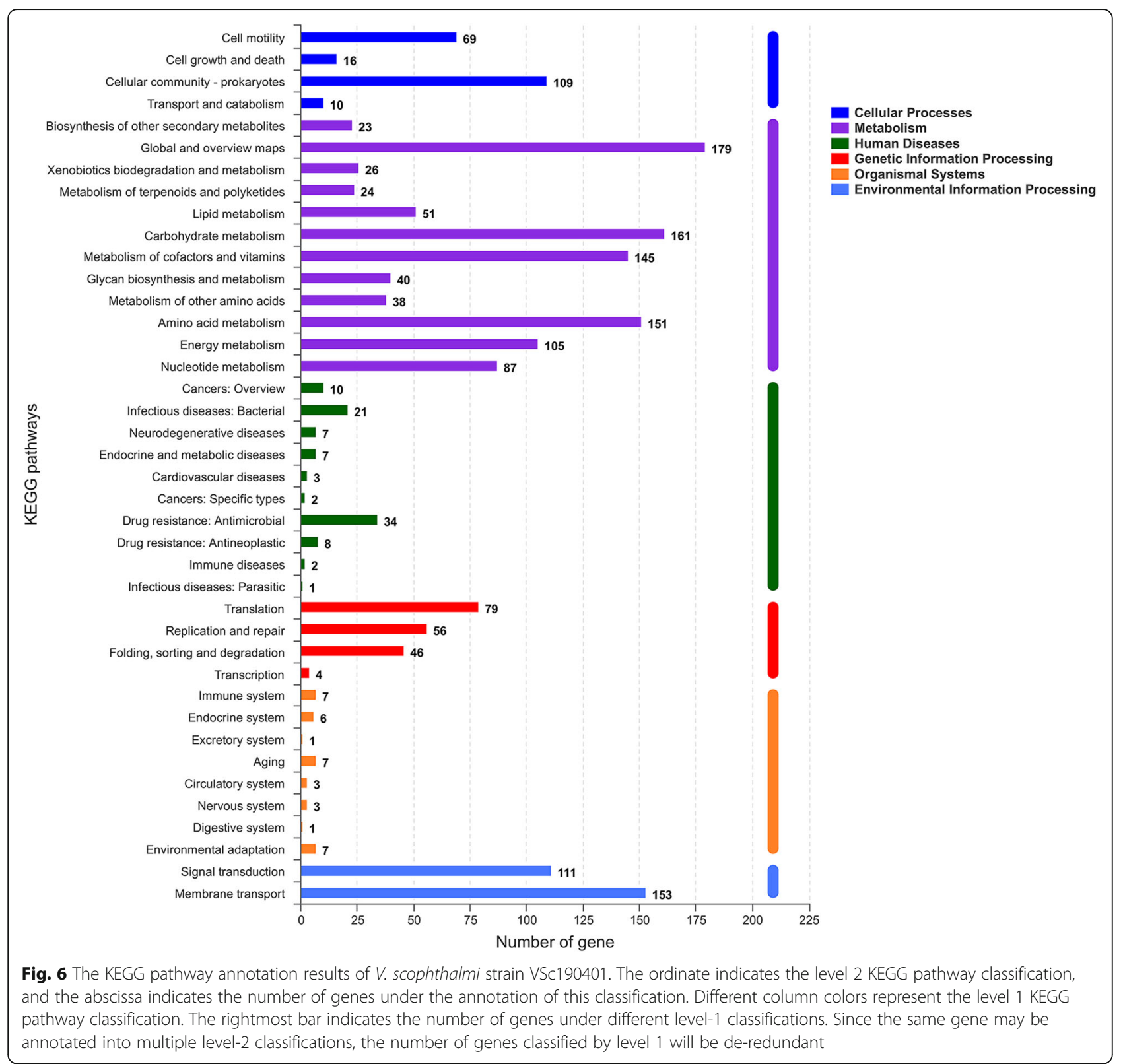

Table 1 The annotation of virulence factors of the strain VSc190401 in VFDB databases

\begin{tabular}{lll}
\hline Virulence primary categories & Virulence Secondary categories & Gene numbers \\
\hline Offensive virulence factors & Toxin & 2 \\
Offensive virulence factors & Secretion system & 13 \\
Offensive virulence factors & Adherence & 81 \\
Offensive virulence factors & Invasion & 11 \\
Defensive virulence factors & Cellular metabolism & 1 \\
Defensive virulence factors & Antiphagocytosis & 21 \\
Defensive virulence factors & Stress protein & 9 \\
Regulation of virulence-associated genes & Regulation & 7 \\
Nonspecific virulence factor & Iron uptake system & 30 \\
\hline
\end{tabular}


of organismal systems were divided into eight categories. Among them, the top three categories with the largest gene number were the immune system (10 genes), aging (11 genes), endocrine system (nine genes), and environmental adaptation (seven genes). The environmental information was divided into two categories, including signal transduction (115 genes) and membrane transport (153 genes). Supplementary Table S3 shows all KEGG pathway annotation information.

Through the IslandViewer online system, 10 genomic islands were predicted to be contained in the whole genome of the strain Vsc190401. They were all located on chromosome I. The longest genomic island was 34,105 $\mathrm{bp}$, and the shortest one was $7883 \mathrm{bp}$. Supplementary Table S4 and Supplementary Figure S1 illustrate their detailed information.

\section{Prediction of virulence genes of the strain VSc190401}

To date, there are few studies on virulence factors of $V$. scophthalmi, and no specific virulence genes have been reported. A total of 334 potential virulence genes were predicted in the whole genome of the strain VSc190401. Moreover, 175 genes had annotation information in VFDB databases, including 107 offensive virulence genes, 31 defensive virulence genes, seven virulence-associated regulation genes, and 30 non-specific virulence genes (Table 1). Supplementary Table S5 shows detailed information.

Among the offensive virulence genes, there were 81 genes related to adhesion, including flagella and pilus formation or motility exercise-related genes, such as Flg, Fle, Flh, Fli, Tcp, PilB/D/G/H/R/T/U, accessory colonization factor $A c f B / D$ [18], adhesion proteins, Lap, OmpU [19] and so on. The results of comparative analysis to the NR database showed that the coverage of coding protein sequences was $96.44-100 \%$, and the identity was $65.8-$ $100 \%$. There were 11 genes related to invasion, including flagella and T4SS genes. The coverage of their coding proteins was $56.14-100 \%$, and the identity was $50-100 \%$ in the NR database. Moreover, 13 genes were related to secretion systems. Their sequence information was all similar to T3SS, T4SS, and T6SS of Gram-negative bacteria. The coverage of their coding proteins was $91.84-100 \%$, and the identity was $56.7-100 \%$. Two toxin genes were similar to Cya gene, the coding proteins of which were suspected as calmodulin-sensitive adenylate cyclasehaemolysin bifunctional protein [20]. The identity of their coding proteins was $98-99.7 \%$.

The defensive virulence genes included 21 antiphagocytosis-related genes, nine stress protein-related genes, and one cellular metabolism-related gene. The antiphagocytosis-related genes included two categories of capsule genes (Cpa, Cps) [21, 22] and alginate genes $(\operatorname{algB} / \mathrm{Q} / U / R / Z, M u c A)$ [23, 24]. The identity of their coding proteins was $85.6-100 \%$. The stress protein-related genes included superoxide dismutase enzyme gene $(\operatorname{sod} B)$, ATP-binding cassette transporter gene (MntABC), DNA repair protein gene $(\operatorname{Rec} N)$, and respiratory metabolism gene $(C l p C P)$ [25]. The identity of the protein sequence was $99-100 \%$. The cellular metabolism-related genes were isocitratelyase coding gene fragments, with a coverage of $100 \%$ and an identity of $100 \%$.

Among the non-specific virulence genes, the most were ATP-binding cassette transporter genes (20 genes, 98.4-100\% protein sequence identity) and bacitracinrelated genes (six genes, $90-100 \%$ protein sequence identity). Moreover, iron uptake system-related genes, such as $F b p A B C$ and $F e o A B(99.4-100 \%$ protein sequence identity), were also found [26, 27].

The virulence-associated regulation genes contained two types of genes, RelA and PhoP. NR database comparative analysis results showed that the coverage of coding protein sequences was $100 \%$, and their identity was $88.4-100 \%$. Other studies have confirmed that RelA and Phop gene regulate the synthesis of bacterial virulence factors as well as their primary and secondary metabolites, thus affecting the bacterial pathogenicity [28, 29]. In addition, the virulence-related gene sequences of ompA (identity $90-100 \%$ ), hemolysin (identity $96.7-100 \%$ ), betahemolysin/cytolysin (identity $98.2-100 \%$ ), enterobactin (identity $99.8-100 \%$ ), and T2SS (identity $97.2-100 \%$ ) were also found in the whole genome of the strain VSc190401.

Further analysis showed that the strain VSc190401 contained 36 secretion system-related genes, including one type I, 11 type II, six type IV, four type VI, 11 SecSRP pathway and three twin-arginine targeting (Tat) pathway. The analysis results also indicated that the strain VSc190401 only had a complete type II secretion system (the detailed information was shown in Supplementary Figure S2). This finding suggested that the type II secretion system was probably the only one product export pathway.

\section{The drug resistance phenotype and genotype analysis of the strain VSc190401}

A total of 38 antibiotics belonging to 10 categories were selected to test the antimicrobial phenotype of strain VSc190401 through the Kirby-Bauer disk diffusion method. The antibiotics of 10 categories were $\beta$-lactam, aminoglycosides, macrolides, tetracyclines, polypeptides, quinolones, sulfonamides, nitrofurans, amphenicols, and others. The results showed that the strain VSc190401 was resistant to all aminoglycosides (including neomycin, streptomycin, kanamycin, gentamicin, amikacin), macrolides (including erythromycin, azithromycin, clarithromycin, acetylspiramycin) and amphenicols (including chloramphenicol and florfenicol). It was sensitive to polypeptides (polymyxin B), quinolones (including pipemidic, nalidixic, 
Table 2 The drug-resistance genes annotation of the strain VSc190401 in CARD databases

\begin{tabular}{llll}
\hline Drug resistance categories & Gene numbers & Drug resistance categories & Gene numbers \\
\hline Pleuromutilin antibiotic & 3 & penem & 3 \\
Carbapenem & 7 & phenicol antibiotic & 12 \\
Sulfonamide antibiotic & 5 & rifamycin antibiotic & 4 \\
Aminoglycoside antibiotic & 10 & isoniazid & 3 \\
Macrolide antibiotic & 45 & triclosan & 11 \\
Glycopeptide antibiotic & 4 & acridine dye & 10 \\
Tetracycline antibiotic & 36 & peptide antibiotic & 14 \\
Monobactam & 5 & lincosamide antibiotic & 1 \\
Diaminopyrimidine antibiotic & 4 & fluoroquinolone antibiotic & 38 \\
Streptogramin antibiotic & 5 & nitroimidazole antibiotic & 6 \\
Glycylcycline & 5 & penam & 27 \\
Sulfone antibiotic & 3 & cephalosporin & 10 \\
Aminocoumarin antibiotic & 9 & nybomycin & 1 \\
Cephamycin & 9 & & \\
\hline
\end{tabular}

fleroxacin, lomefloxacin, ciprofloxacin, ofloxacin, norfloxacin, enrofloxacin), sulfonamides (sulfamethoxazole) and nitrofurans (including furazolidone). In $\beta$-lactam antibiotics, the strain showed resistance to cefoperazone, ceftizoxime, cefotaxime, ceftriaxone, ceftazidime, cefradine and oxacillin, while it was sensitive to penicillin, ampicillin, cefalexin and cefazolin. In tetracyclines antibiotics, the strain showed resistance to doxycycline, while it was sensitive to minocycline and tetracycline. Among other antibiotics, the strain showed resistance to rifampicin, while it was sensitive to novobiocin.

The results of Blast analysis in the CARD database showed that 180 drug resistance genes belonging to 27 categories were found in the whole genome of the strain VSc190401 (Table 2). In terms of drug resistance phenotype and genotype correlation, the strain VSc190401 contained the streptomycin-resistant genes, gidB and $v a t B$ [30], and rifampin-resistant genes, $r p o B$ [31]. The phenotype was consistent with the genotype. The novobiocin-resistant genes, ala $S$ and $c y s B$ [32], nalidixicresistant genes, $\operatorname{gyr} A / B$ and $\operatorname{par} C / E$ [33], tetracyclineresistant genes, tet31/34/35/B/R/S/T and adeR [34], ciprofloxacin-resistant genes, pat $A / B$ [35], and bpolymyxin B-resistant genes, $P m r A / C / E, L p x A / C$ and $\operatorname{ros} B$ [36], were found in the whole genome, while the strain was sensitive to these drugs. The phenotype was inconsistent with the genotype. Besides, the multiple resistance genes and complex genes of different antibiotics were also found in the strain, such as multiple resistance genes, $d r r A$ [37], $c p x A$ and $o m p R$ [38], multidrug efflux pump systems, including $A B C$ transporter superfamily of proteins $m s b A$ [39]; two-component signal transduction system, EvgAS [40]; two-component regulatory system, BaeSR [41]; an activator of $m \operatorname{trCDE}$ multidrug-resistance efflux pump, mtrA [42]; MexEF-Opr multidrug efflux systems [43]; two-component regulatory systems, $\operatorname{VanRS}$ [44] and ArlRS [45]. These results showed that the resistance mechanism of the strain VSc190401 might be complex. Phenotypes of multiple drug resistance without specific resistance genes suggested that there were multiple drug metabolism pathways. Supplementary Table S6 shows the annotation information of all drug resistance genes.

\section{Predictive analysis of pathogen-host interaction between the strain VSc190401 and host}

According to the annotation results of the PHI database, the strain VSc190401 contained 518 genes related to pathogen-host interaction. Among them, there were 346 genes related to reduced virulence, 44 genes related to loss of pathogenicity, 36 genes related to hypervirulence, 12 genes related to lethal factors, 11 genes related to effector, three genes related to chemical resistance, and two genes related to chemical sensitivity, and there were 108 genes with unaffected pathogenicity. The hypervirulence and effector genes were the key genes in correlation with pathogenicity. The hypervirulence of the strain VSc190401 included T3SS function genes, esaN and GdpX1, virulence regulatory factors, MorA, $c c p E, \operatorname{RsmA}, \operatorname{rax} P$ and $C d p R$ [46-49], two-component sensor kinase, BfiS [50], histidine kinase and response regulator two-component system, $T c r X / Y$ [51], and iron ion transporters, $f e o B$ and $p c h D$. The effector genes of the strain VSc190401 included T6SS components, $\operatorname{VgrG}$ and $c l p V$ [52], phospholipase $\mathrm{D}$ effector, $\operatorname{LpdA}$ [53], pleiotropic effector of virulence synthesis and pathogenicity attenuation, RpiRc [54]. Supplementary Table S7 lists the detailed annotation information of pathogen-host interaction genes. 


\section{Conclusions}

The whole genome of pathogenic $V$. scophthalmi strain VSc190401 was 3,541,838 bp in length, including two circular chromosomes with the sizes of 3 , $286,294 \mathrm{bp}$ and $202,664 \mathrm{bp}$, and two plasmids with the sizes of $24,538 \mathrm{bp}$ and $28,342 \mathrm{bp}$, and this genome contained 3185 coding genes. The result of gene functional annotation indicated that 2648 genes were annotated into 22 types of genes in the COG database, accounting for $83.14 \%$ of total genes. Moreover, 2298 genes were annotated into three classifications in the Blast2GO database, accounting for $72.15 \%$ of total genes. Besides, 1915 genes were annotated into 196 known KEGG metabolic pathways, accounting for $60.13 \%$ of total genes. The analysis results based on the VFDB database showed that the strain VSc190401 contained 334 potential virulence genes, including four secretion systems of T1SS, T2SS, T4SS, T6SS related genes, and many different reported virulence genes. However, it only had one complete T2SS secretion system. Blast results in the CARD database showed that the strain contained 180 drug resistance genes belonging to 27 antibiotic resistance categories. However, many phenotypic resistance antibiotics were not related to drug resistance genes in the whole genome. Comparison analysis with the PHI database obtained 809 genes related to pathogen-host interaction, including a variety of regulatory factors or regulatory systems, as well as T3SS and T6SS functional genes. The whole-genome analysis suggested that pathogenic $V$. scophthalmi strain VSc190401 might have a complex molecular mechanism of drug resistance and pathogenicity, which need to be further explored in-depth research.

\section{Materials and methods The strain}

$V$. scophthalmi strain VSc190401 was isolated from the liver of diseased half-smooth tongue sole (Cynoglossus semilaevis) cultured in an indoor farm. The symptoms of the diseased fish were hydrops in the abdomen and intestine, as well as enteritis. They were anesthetized and dissected by aseptic manipulation. Subsequently, their liver and intestine were sliced and homogenized with sterilized $\mathrm{NaCl}$ solution (1.5\%), which were then cultured on a tryptic soy broth (TSB) agar medium plate containing $1.5 \% \mathrm{NaCl}$ using streaking inoculation method. All plates were incubated at $28^{\circ} \mathrm{C}$ for $24 \mathrm{~h}$ to $36 \mathrm{~h}$ to observe colony morphology. The largest single colonies with identical forms were considered as dominant bacteria. One of them was picked out for purification culture and used in further experiments.

The isolated strain was purified on TSB medium three times. The purified strain was used to prepare the living bacterial suspension at a density of $1.0 \times 10^{6} \mathrm{CFU} / \mathrm{mL}$. The strain pathogenicity was determined through an artificial challenge experiment by intraperitoneal injection. Half-smooth tongue sole and turbot with an average body weight of $50 \mathrm{~g}$ were purchased from a farm as the experimental animals. A total of 90 half-smooth tongue sole and 90 turbot were cultured in an indoor aquatic experiment system for 10 days to check their health firstly. Subsequently, the healthy fish were divided into six groups with 30 fish in each group, including one experimental group, one negative control group, and one blank control group of half-smooth tongue sole, and one experimental group, one negative control group, and one blank control group of turbot. Each group of fish was cultured in a 300-1 aerated seawater tank. The experimental groups were intraperitoneally injected with bacterial suspension, the negative control group was injected with $1.5 \%$ sterile $\mathrm{NaCl}$ solution, and no injection was given in the blank control group. The injection dose was $0.1 \mathrm{~mL}$ bacterial suspension per $50 \mathrm{~g}$ body weight. During the experiment, the water was changed by $30 \%$ every day, and the temperature was maintained at $19 \pm$ $1{ }^{\circ} \mathrm{C}$. Fish were fed once a day.

When the fish in the experimental group developed symptoms, the dominant bacteria were isolated from the lesions, followed by purification and identification using the TSB agar medium plate [55]. After the isolated strain was identified as $V$. scophthalmi strain, its whole genome was sequenced on the Illumina HiSeq X platform. Meanwhile, the antibiotic resistance phenotype of this strain was detected using the Kirby-Bauer disk diffusion method. A total of 38 antibiotics were tested.

After the artificial challenge experiment finish, all the experimental fish in the negative control groups and blank control groups were returned to farm for continue farming. The fish in experimental groups were hypothermal shocked with ice-water mixture, until anesthesia. Subsequently, carbon dioxide was aerated in to the water to suffocate these fish to death. The dead fish were soaked in chlorine dioxide disinfectant at concentration of $1 \times 10^{-4} \mathrm{mg} / \mathrm{L}$ for 3 hours, then they were sent to the experimental waste disposal station for harmless treatment.

\section{Genomic DNA extraction, sequencing, and assembly}

Genomic DNA of $V$. scophthalmi strain VSc190401 was extracted using Wizard $^{\circ}$ genomic DNA purification kit (Promega Biotechnology Co., Ltd., Beijing, China). The quality of extracted DNA was tested using a Qubit fluorometer (Thermo Fisher Scientific, Waltham, MA, USA) and a Nanodrop spectrophotometer (Thermo Fisher Scientific, Waltham, MA, USA). The purified genomic DNA was quantitatively analyzed by the TBS-380 fluorometer (Turner BioSystems Inc., Sunnyvale, CA, USA). Qualified genomic DNA was cut into $>10-\mathrm{kb}$ 
fragments via G-tubes (Covaris Inc., Woburn, MA, USA) and used to construct the SMARTbell DNA database after terminal repair. Genome sequencing was conducted by Majorbio Biotechnology Co., Ltd. (Shanghai, China) using the Illumina HiSeq X sequencer. The obtained SMRT original sequence data were de novo assembled by hierarchical genomic assembly process (HGAP), and the quality of the newly assembled genome was corrected and verified by overlap layout consensus (OLC) and Quiver consensus algorithm to obtain the whole genome $[56,57]$.

\section{Genome component analysis and functional annotation}

Glimmer software was used to predict the coding sequences (CDSs) in the genome. RepeatMasker software was used to predict tandem repeat sequences [58]. The rRNAs and tRNAs belonging to non-coding RNAs were predicted by rRNAmmer software [59] and tRNAscan software [60], respectively. Furthermore, different databases, such as Gene Ontology (GO), Kyoto Encyclopedia of Genes and Genomes (KEGG), Cluster of Orthologous Groups (COG), Non-Redundant Protein Sequence Database in NCBI (NR), UniProt/Swiss-Prot, Pfam, Virulence Factors of Pathogenic Bacteria (VFDB), Pathogen Host Interactions (PHI) and the Comprehensive Antibiotic Research Database (CARD), were used to annotate the functions of coding genes. Finally, the genome circle map was drawn and annotated using the Circos software (http://circos.ca/). The genomic islands were predicted through IslandViewer online system (http://www.patho genomics.sfu.ca/islandviewer/upload/).

\section{Phylogenetic analysis}

The complete reference genome sequences were downloaded from the NCBI database, and comparative analysis was performed based on the average nucleotide identity (ANI) value described by Richter and Rossello [61]. The OAT software (https://www.ezbiocloud.net/tools/orthoani) was used for ANI analysis [62]. The bacterial strains of the reference genome were as follows: $V$. scophthalmi VS-12, $V$. scophthalmi VS-05, $V$. cholerae RFB05, $V$. anguillarum ATCC-68554, V. rotiferianus CAIM 577, V. harveyi ATCC 33843, V. parahaemolyticus FORC_008 and V. vulnificus ATCC 27562.

\section{Supplementary Information}

The online version contains supplementary material available at https://doi. org/10.1186/s12866-020-02028-7.

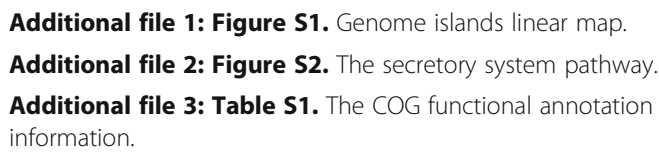

Additional file 4: Table S2. The GO functional annotation information. Additional file 5: Table S3. The KEGG pathway annotation information.
Additional file 6: Table S4. The gene information of genomic islands on chromosome 1 .

Additional file 7: Table S5. The virulence factors annotation information.

Additional file 8: Table S6. The drug-resistance genes annotation information.

Additional file 9: Table S7. The PHI genes annotation information.

\section{Abbreviations}

COG: Clusters of Orthologous Groups of proteins; GO: Gene Ontology; KEGG: Kyoto Encyclopedia of Genes and Genomes; VFDB: Virulence Factors of Pathogenic Bacteria; NR: Non-Redundant Protein Sequence Database in NCBI; PHI: Pathogen Host Interactions; CARD: Comprehensive Antibiotic Research Database; HGAP: Hierarchical genomic assembly process; OLC: Overlap layout consensus; CODs: Coding sequences; ANI: Average nucleotide identity

\section{Acknowledgements}

Not applicable.

\section{Authors' contributions}

ZZ isolated this strain, designed the research, performed antibiotic resistance phenotype experiment and phylogenetic analysis, wrote the draft. YXY sequenced the whole genome and analyzed COG, GO, KEGG, and NR database. YGW examined the experimental design and polished the language. XL and LFW performed the artificial infection experiment; $\mathrm{HZ}$ analyzed VFDB and PHI database. MJL analyzed CARD database. BL participated in the artificial infection experiment. All authors read and approved the final manuscript.

\section{Funding}

This work was funded by National Key R\&D Program of China (Grant: 2019YFD0900104). Projects of International Exchange and Cooperation in Agriculture, Ministry of Agriculture and Rural Affairs of China-Science, Technology and Innovation Cooperation in Aquaculture with Tropical Countries along the Belt and Road. The project of Taishan industry leading talent (LJNY201802).

\section{Availability of data and materials}

The whole genome sequence of Vibrio scophthalmi strain VSc190401 has been deposited in the NCBI GenBank server under the SRA accession number PRJNA628013 for chromosome 1, chromosome 2, and the plasmids.

\section{Ethics approval and consent to participate}

All the animal-related procedures were approved by the Institutional Animal Care \& Use Committee (IACUC) of Yellow Sea Fisheries Research Institute, Chinese Academy of Fishery Sciences and conducted in accordance with the China Government Principles for the Utilization and Care of Vertebrate Animals Used in Testing, Research, and Training (http://www.gov.cn/gongbao/ content/2011/content_1860757.htm).

\section{Consent for publication}

All the authors agree to publish this paper.

\section{Competing interests}

The authors declare that they have no competing interests.

Received: 10 May 2020 Accepted: 30 October 2020

Published online: 11 November 2020

\section{References}

1. Cerdàg-cuéllar M, Rossellò-Mora RA, Lalucat J, Jofre J, Blanch A. Vibrio scophthalmi sp. nov., a new species from turbot (Scophthalmus maximus). Int J Syst Bacteriol. 1997;47(1):58-61. https://doi.org/10.1099/ 00207713-47-1-58.

2. Sawabe T, Kita-Tsukamoto K, Thompson FL. Inferring the evolutionary history of vibrios by means of multilocus sequence analysis. J Bacteriol. 2007;189(21):7932-6. https://doi.org/10.1128/JB.00693-07. 
3. Tarazona E, Pérez-Cataluña A, Lucena T, Arahal DR, Macián MC, Pujalte MJ. Multilocus sequence analysis of the redefined clade scophthalmi in the genus Vibrio. Syst Appl Microbiol. 2015;38:169-75. https://doi.org/10.1016/j. syapm.2015.03.005.

4. Blanch AR, Alsina M, Simón M, Jofre J. Determination of bacteria associated with reared turbot (Scophthalmus maximus) larvae. J Appl Microbiol. 1997; 82:729-34. https://doi.org/10.1046/j.1365-2672.1997.00190.x.

5. Qiao G, Lee DC, Woo SH, Li H, Xu D-H, Park SI. Microbiological characteristics of Vibrio scophthalmi isolates from diseased olive flounder Paralichthys olivaceus. Fish Sci. 2012;78:853-63. https://doi.org/10.1007/ s12562-012-0502-8.

6. Soffientino B, Gwaltney T, Nelson DR, Specker JL, Mauel M, Gómez-Chiarri M. Infectious necrotizing enteritis and mortality caused by Vibrio carchariae in summer flounder Paralichthys dentatus during intensive culture. Dis Aquat Org. 1999;38:201-10. https://doi.org/10.3354/dao038201.

7. Sitjà-Bobadilla A, Pujalte MJ, Bermejo A, Garay E, Alvarez-Pellitero P, PérezSánchez J. Bacteria associated with winter mortalities in laboratory-reared common dentex (Dentex dentex L.). Aquac Res. 2007;38:733-9. https://doi. org/10.1111/j.1365-2109.2007.01719.x.

8. Hidalgo BR, Cleenwerck I, Balboa S, Wachter MD, Thompson FL, Swings $J$, et al. Diversity of Vibrios associated with reared clams in Galicia (NW Spain). Syst Appl Microbiol. 2008;31:215-22. https://doi.org/10.1016/j. syapm.2008.04.001.

9. Valdenegro-Vega V, Naeem S, Carson J, Bowman JP, Tejedor RJL, Nowak B. Culturable microbiota of ranched southern bluefin tuna (Thunnus maccoyi Castelnau). J Appl Microbiol. 2013;115(4):923-32. https://doi.org/10.1111/ jam.12286.

10. Lee N-S, Kim D-J, Lee B-I, Kim SK, Kim MS, Kim YC. Vibrio scophthalmi infection in Japanese eel Anguilla japonica during seawater adaption. J fish Pathol. 2012;25(3):173-80. (in Korean with English abstract). https://doi.org/ 10.7847/jfp.2012.25.3.173.

11. Kang BJ. A study on the characteristics of bacteria isolated from cultured flouders Paralichthys olivaceus showing disease symptoms in Jeju area of Korea. CheJu National University; the dissertation for Ph. D degree, 2003. (in Korean with English abstract).

12. Zheng Z. Epizootic investigation and aetiological study on the bacterial diseases in cultured turbot (Scophthalmus maximus): Ocean University of China; the dissertation for Master degree; 2004. (in Chinese with English abstract).

13. Thompson FL, Gevers D, Thompson CC, Dawyndt P, Naser S, Hoste B, et al. Phylogeny and molecular identification of Vibrios on the basis of multilocus sequence analysis. Appl Environ Microbiol. 2005;71(9):5107-15. https://doi. org/10.1128/AEM.71.9.5107-5115.2005.

14. Montero AB, Austin B. Characterization of extracellular products from an isolate of Vibrio harveyi recovered from diseased post-larval Penaeus vannamei (bonne). J Fish Dis. 1999;22:377-86. https://doi.org/10.1046/j.13652761.1999.00189.x.

15. Qiao G, Jang I-K, Won KM, Woo SH, Xu D-H, Park SI. Pathogenicity comparison of high- and low-virulence strains of Vibrio scophthalmi in olive flounder Paralichthys olivaceus. Fish Sci. 2013;79:99-109. https://doi.org/10. 1007/s12562-012-0567-4

16. Cui HJ, Meng YX, Feng WQ, Zhao Q, Cheng MY. Identification and antimicrobial susceptibility test of Vibrio scophthalmi isolated from the intestine of cultured turbot Scophthalmus maximus. Fish Sci. 2017;36:125-31 (in Chinese with English abstract).

17. Wang L, Wang YG, Zhang Z, Chen GH, Liao MJ, Chen X, et al. Diversity and drug resistance of bacterial pathogens isolated from bacterial ascetic disease in cultured turbot Scophthalmus maximus. Prog Fish Sci. 2017;38: 17-24 (in Chinese with English abstract)

18. Cai $\mathrm{S}$, Cheng $\mathrm{H}$, Pang $\mathrm{H}$, Jian J, Wu Z. AcfA is an essential regulator for pathogenesis of fish pathogen Vibrio alginolyticus. Vet Microbiol. 2018;213: 35-41. https://doi.org/10.1016/j.vetmic.2017.11.016.

19. Kim H, Bhunia AK. Secreted Listeria adhesion protein (lap) influences lap-mediated Listeria monocytogenes paracellular translocation through epithelial barrier. Gut Pathog. 2013;5:16. https://doi.org/10.1186/17574749-5-16.

20. Glaser P, Sakamoto H, Bellalou J, Ullmann A, Danchin A. Secretion of cyclolysin, the calmodulin-sensitive adenylate cyclase-haemolysin bifunctional protein of Bordetella pertussis. EMBO J. 1988;7(12):3997-4004. https://doi.org/10.1002/j.1460-2075.1988.tb03288.x.
21. Salter SJ, Hinds J, Gould KA, Lambertsen L, Hanage WP, Antonio M, et al. Variation at the capsule locus, cps, of mistyped and non-typable Streptococcus pneumoniae isolates. Microbiology. 2012;158:1560-9. https:// doi.org/10.1099/mic.0.056580-0.

22. Waite RD, Penfold DW, Struthers JK, Dowson CG. Spontaneous sequence duplications within capsule genes cap8E and tts control phase variation in Streptococcus pneumoniae serotypes 8 and 37. Microbiology. 2003;149:497504. https://doi.org/10.1099/mic.0.26011-0.

23. Núñez C, León R, Guzmán J. Espín G, Soberón-Chávez G. role of Azotobacter vinelandii mucA and mucC gene products in alginate production. J Bacteriol. 2000;182(23):6550-6. https://doi.org/10.1128/JB.182.23.6550-6556.2000.

24. Gao J. Screening of alginate lyase producing strain and cloning and expression of its gene. Dalian University of Technology; the dissertation for Master degree, 2018. (in Chinese with English abstract).

25. Mashruwala AA, Eilers BJ, Fuchs AL, Norambuena J, Earle CA, Guchte A, et al The ClpCP complex modulates respiratory metabolism in Staphylococcus aureus and is regulated in a SrrAB-dependent manner. J Bacteriol. 2019; 201(15):e00188-19. https://doi.org/10.1128/JB.00188-19.

26. Robey M, Cianciotto NP. Legionella pneumophila feoAB promotes ferrous iron uptake and intracellular infection. Infect Immun. 2002;70(10):5659-69. https://doi.org/10.1128/IAl.70.10.5659-5669.2002.

27. Adhikari P, Berish SA, Nowalk AJ, Veraldi KL, Morse SA, Mietzner TA. The fbpABC locus of Neisseria gonorrhoeae functions in the periplasm-to-cytosol transport of iron. J Bacteriol. 1996;178(7):2145-9. https://doi.org/10.1128/JB. 178.7.2145-2149.1996.

28. Haralalka S, Nandi S, Bhadra RK. Mutation in the relA Gene of Vibrio cholerae affects in vitro and in vivo expression of virulence factors. J Bacteriol. 2003; 185(16):4672-82. https://doi.org/10.1128/JB.185.16.4672-4682.2003.

29. Wei C, Ding T, Chang C, Yu C, Li X, Liu Q. Global regulator PhoP is necessary for motility, biofilm formation, exoenzyme production, and virulence of Xanthomonas citri subsp. citri on citrus plants. Genes. 2019;10(5):340. https:// doi.org/10.3390/genes10050340.

30. Smittipat $N$, Juthayothin T, Billamas P, Jaitrong S, Rukseree K, Dokladda K, et al. Mutations in rrs, rpsL and gidB in streptomycin-resistant mycobacterium tuberculosis isolates from Thailand. J Glob Antimicrob Resist. 2016:4:5-10. https://doi.org/10.1016/j.jgar.2015.11.009.

31. Zaw MT, Emran NA, Lin Z. Mutations inside rifampicin-resistance determining region of $r p o B$ gene associated with rifampicin-resistance in Mycobacterium tuberculosis. J Infect Public Health. 2018;11:605-10. https:// doi.org/10.1016/j.jiph.2018.04.005

32. Milija J, Lilic M, Janjusevic R, Jovanovic G, Savic DJ. tRNA synthetase mutants of Escherichia coli K-12 are resistant to the gyrase inhibitor novobiocin. J Bacteriol. 1999;181(9):2979-83 http://www.ncbi.nlm.nih. gov/pubmed/10217798

33. Bae DH, Baek HJ, Jeong SJ, Lee YJ. Amino acid substitutions in gyrA and parC associated with quinolone resistance in nalidixic acid-resistant Salmonella isolates. Ir Vet J. 2013;66:23. https://doi.org/10.1186/2046-048166-23.

34. Costello SE, Gales AC, Morfin-Otero R, Jones RN, Castanheira M. Mechanisms of resistance, clonal expansion, and increasing prevalence of Acinetobacter baumannii strains displaying elevated tigecycline MIC values in Latin America. Microb Drug Resist. 2016;22(4):253-8. https://doi.org/10.1089/mdr. 2015.0168 .

35. Lupien A, Billal DS, Fani F, Soualhine H, Zhanel GG, Leprohon $P$, et al. Genomic characterization of ciprofloxacin resistance in a laboratoryderived mutant and a clinical isolate of Streptococcus pneumoniae. Antimicrob Agents Chemother. 2013;57(10):4911-9. https://doi.org/10. 1128/AAC.00418-13.

36. Zhang W, Aurosree B, Gopalakrishnan B, Balada-Llasat J-M, Pancholi V, Pancholi $P$. The role of $L p X A / C / D$ and $p m r A / B$ gene systems in colistinresistant clinical strains of Acinetobacter baumannii. Front Lab Med. 2017;1: 86-91. https://doi.org/10.1016/j.flm.2017.07.001.

37. Kardan-Yamchi J, Kazemian H, Haeili M, Harati AA, Amini S, Feizabadi MM. Expression analysis of 10 efflux pump genes in multidrug-resistant and extensively drug-resistant Mycobacterium tuberculosis clinical isolates. J Glob Antimicrob Resist. 2019;17:201-8. https://doi.org/10.1016/j.jgar.2019.01.003.

38. Lin X, Wang C, Guo C, Tian Y, Li H, Peng X. Differential regulation of OmpC and OmpF by AtpB in Escherichia coli exposed to nalidixic acid and chlortetracycline. J Proteome. 2012;75:5898-910. https://doi.org/10.1016/j. jprot.2012.08.016. 
39. Chiu H-C, Lin T-L, Yang J-C, Wang J-T. Synergistic effect of imp/ostA and msbA in hydrophobic drug resistance of Helicobacter pylori. BMC Microbiol. 2009;9:136. https://doi.org/10.1186/1471-2180-9-136.

40. Eguchi Y, Oshima T, Mori H, Aono R, Yamamoto K, Ishihama A, et al. Transcriptional regulation of drug efflux genes by EvgAS, a two-component system in Escherichia coli. Microbiology. 2003;149:2819-28. https://doi.org/ 10.1099/mic.0.26460-0.

41. Baranova N, Nikaido $H$. The BaeSR two-component regulatory system activates transcription of the yegMNOB ( $m d t A B C D$ ) transporter gene cluster in Escherichia coli and increases its resistance to novobiocin and deoxycholate. J Bacteriol. 2002;184(15):4168-76. https://doi.org/10.1128/JB. 184.15.4168-4176.2002.

42. Warner DM, Folster JP, Shafer WM, Jerse AE. Regulation of the MtrC-MtrDMtrE efflux-pump system modulates the in vivo fitness of Neisseria gonorrhoeae. J Infect Dis. 2007;196:1804-12. https://doi.org/10.1086/522964.

43. Sobel ML, Neshat S, Poole K. Mutations in PA2491 (mexS) promote MexTdependent mexEF-oprN expression and multidrug resistance in a clinical strain of Pseudomonas aeruginosa. J Bacteriol. 2005;187(4):1246-53. https:// doi.org/10.1128/JB.187.4.1246-1253.2005.

44. Silva JC, Haldimann A, Prahalad MK, Walsh CT, Wanner BL. In vivo characterization of the type a and B vancomycin-resistant enterococci (VRE) VanRS two-component systems in Escherichia coli: a nonpathogenic model for studying the VRE signal transduction pathways. Proc Natl Acad Sci. 1998; 95:11951-6. https://doi.org/10.1073/pnas.95.20.11951.

45. Memmi G, Nair DR, Cheung A. Role of ArIRS in autolysis in methicillinsensitive and methicillin-resistant Staphylococcus aureus strains. J Bacteriol. 2012;194(4):759-67. https://doi.org/10.1128/JB.06261-11.

46. Phippen CW, Mikolajek H, Schlaefli HG, Keevil CW, Webb JS, Tews I. Formation and dimerization of the phosphodiesterase active site of the Pseudomonas aeruginosa MorA, a bi-functional c-di-GMP regulator. FEBS Lett. 2014;588:4631-6. https://doi.org/10.1016/j.febslet.2014.11.002.

47. Hartmann T, Baronian G, Nippe N, Voss M, Schulthess B, Wolz C, et al. The catabolite control protein $\mathrm{E}(\mathrm{C} \mathrm{CpE})$ affects virulence determinant production and pathogenesis of Staphylococcus aureus. J Biol Chem. 2014;289(43): 29701-11. https://doi.org/10.1074/jbc.M114.584979.

48. Zhao J, Yu X, Zhu M, Kang H, Ma J, Wu M, et al. Structural and molecular mechanism of $\mathrm{CdpR}$ involved in quorum-sensing and bacterial virulence in Pseudomonas aeruginosa. PLoS Biol. 2016;14(4):e1002449. https://doi.org/10. 1371/journal.pbio.1002449.

49. Shen $Y$, Sharma $P$, Silva FG, Ronald $P$. The Xanthomonas oryzae pv. oryzae raxP and raxQ genes encode an ATP sulphurylase and adenosine- ${ }^{\prime}$ phosphosulphate kinase that are required for AvrXa21 avirulence activity. Mol Microbiol. 2002;44(1):37-48. https://doi.org/10.1046/j.1365-2958.2002.02862.x.

50. Pletzer D, Mansour SC, Wuerth K, Rahanjam N, Hancock REW. New mouse model for chronic infections by gram-negative bacteria enabling the study of anti-infective efficacy and host-microbe interactions. MBio. 2017;8: e00140-17. https://doi.org/10.1128/mBio.00140-17.

51. Bhattacharya M, Das AK. Inverted repeats in the promoter as an autoregulatory sequence for TcrX in Mycobacterium tuberculosis. Biochem Biophys Res Commun. 2011;415:17-23. https://doi.org/10.1016/ j.bbrc.2011.09.143.

52. Hachani A, Lossi NS, Hamilton A, Jones C, Bleves S, Albesa-Jové D, et al. Type VI secretion system in Pseudomonas aeruginosa. J Biol Chem. 2011. 286(14):12317-27. https://doi.org/10.1074/jbc.M110193045.

53. Schroeder GN, Aurass P, Oates CV, Tate EW, Hartland EL, Flieger A, et al. Legionella pneumophila effector LpdA is a palmitoylated phospholipase D virulence factor. Infect Immun. 2015;83:3989-4002. https://doi.org/10.1128/ |Al.00785-15.

54. Gaupp R, Wirf J, Wonnenberg B, Biegel T, Eisenbeis J, Graham J, et al. RpiRc is a pleiotropic effector of virulence determinant synthesis and attenuates pathogenicity in Staphylococcus aureus. Infect Immun. 2016;84:2031-41. https://doi.org/10.1128/IAl.00285-16.

55. Zhang Z, Yu Y-X, Wang K, Wang Y-G, Jiang Y, Liao M-J, et al. First report of skin ulceration caused by Photobacterium damselae subsp. damselae in netcage cultured black rockfish (Sebastes schlegeli). Aquaculture. 2019;503:1-7. https://doi.org/10.1016/j.aquaculture.2018.12.088.

56. Chin C-S, Alexander DH, Marks P, Klammer AA, Drake J, Heiner C, et al. Nonhybrid, finished microbial genome assemblies from long-read SMRT sequencing data. Nat Methods. 2013;10(6):563-9. https://doi.org/10.1038/ nmeth.2474
57. Myers EW, Sutton GG, Delcher AL, Dew IM, Fasulo DP, Flanigan MJ, et al. A whole-genome assembly of Drosophila. Science. 2000;287(5461):2196-204. https://doi.org/10.1126/science.287.5461.2196.

58. Tarailo-Graovac $\mathrm{M}$, Chen $\mathrm{N}$. Using repeatmasker to identify repetitive elements in genomic sequences. Curr Protoc Bioinforma. 2009;25:4.10.1-4. 10.14. https://doi.org/10.1002/0471250953.bi0410s25.

59. Lagesen K, Hallin P, Rødland EA, Stærfeldt H-H, Rognes T, Ussery DW. RNAmmer: consistent and rapid annotation of ribosomal RNA genes. Nucleic Acids Res. 2007;35(9):3100-8. https://doi.org/10.1093/nar/gkm160.

60. Lowe TM, Eddy SR. tRNAscan-SE: a program for improved detection of transfer RNA genes in genomic sequence. Nucleic Acids Res. 1997;25(5): 955-64. https://doi.org/10.1093/nar/25.5.955.

61. Richter M, Rosselló-Móra R. Shifting the genomic gold standard for the prokaryotic species definition. Proc Natl Acad Sci U S A. 2009;106(45):1912631. https://doi.org/10.1073/pnas.0906412106.

62. Lee I, Kim YO, Park S-C, Chun J. OrthoANI: an improved algorithm and software for calculating average nucleotide identity. Int J Syst Evol Microbiol. 2016;66(2):1100-3. https://doi.org/10.1099/ijsem.0.000760.

\section{Publisher's Note}

Springer Nature remains neutral with regard to jurisdictional claims in published maps and institutional affiliations.

\section{Ready to submit your research? Choose BMC and benefit from:}

- fast, convenient online submission

- thorough peer review by experienced researchers in your field

- rapid publication on acceptance

- support for research data, including large and complex data types

- gold Open Access which fosters wider collaboration and increased citations

- maximum visibility for your research: over $100 \mathrm{M}$ website views per year

At BMC, research is always in progress.

Learn more biomedcentral.com/submissions 